\title{
CCSVI: Hope, Hype or Snake Oil?
}

Can. J. Neurol. Sci. 2010; 37: 716

Multiple Sclerosis (MS), a disease first described during the mid-19th century, is generally accepted as being a chronic autoimmune disorder that results from the interaction of yet unidentified environmental factors and genetically susceptible individuals. Accordingly multiple sclerosis has been treated for decades with Immuno-modulators, these drugs, however, have met with, at best, moderate success. A vascular surgeon from Italy, Dr. Paolo Zamboni, re-introduces a semi-novel theory to the world of multiple sclerosis ${ }^{1-3}$ : Chronic CerebroSpinal Venous Insufficiency or CCSVI, as the cause of multiple sclerosis and he states that endovascular procedures can cure it. Over night, and through international media, Canadian multiple sclerosis patients are planning their surgery and envision to travel to far-away countries such as Poland, India and Cuba for "Vascular Tourism".

In this issue of CJNS, a comprehensive review article on CCSVI by Dr. Bryce Weir appears timely ${ }^{4}$. Dr. Weir is a prestigious retired neurovascular surgeon who has been the head in Calgary (now Professor Emeritus at the University of Alberta) and at The University of Chicago (now Professor Emeritus at University of Calgary) where he has been the Chief of Neurosurgery and Director of the Brain Research Institute of the Pritzker School of Medicine. He retired from University of Calgary after being Vice-President of Medical Affairs ${ }^{5}$. Such a track record witnesses his knowledge as a neurovascular surgeon, his wisdom as Emeritus. His eagle's view of the problem could help some Multiple Sclerosis researchers who have not been able to calm the popular enthusiasm which followed non-critical presentations of Zamboni's results by some journalists in the Canadian Television ${ }^{6}$ and Printed press ${ }^{7}$. For a chronological critical review of the controversy we refer the reader to: The Zamboni myth: why "CCSVI" is surreal ${ }^{8}$.

Dr. Weir extensively discusses the venous outflow from the brain and spinal cord from an anatomical and a physiological point of view. It appears to us that neurologists generally have a very limited knowledge of the brain venous drainage. The most valuable piece of information being the variability in the anatomy of the venous outflow from the brain and spinal cord between individuals, how asymmetrical it could be in the same individual, and how it varies with the position of the body and changes in thoracic and abdominal pressures. As Dr. Weir describes the venous anastomoses between the jugular and vertebral venous systems, which are extensive, it becomes difficult to admit that venous flow would not overcome any obstruction without compromising the brain or spinal cord drainage/pressure. Next, Dr. Weir searches among disorders in which cerebral blood drainage is affected, if any has been reported to precede or be associated with the onset of MS or any form of demyelination. He was not able to find any such report. $\mathrm{He}$ further describes reasons that would support the responsibility of CCSVI in MS and reasons that would not. $\mathrm{He}$ concludes that, as perhaps intuitive to most of us, further studies by independent investigators need to be performed before any conclusion can be reached regarding the actual relationship between CCSVI and MS. He warns against starting to treat such abnormalities before further confirmation of this theory is obtained. At the present time, most published attempts seem not to have succeeded. ${ }^{9,10}$

The recent story of CCSVI, with Canadian MS patients becoming activists, Canadian investigators having difficulties to respond in a timely fashion and the MS Society being torn in between will certainly mark the beginning of a new era in the relationship between MS patients, and the regulatory powers. We all hope that the politicians will not be overwhelmed by their customers.

\section{Joel Oger, Mona Alkhajawah \\ University of British Columbia \\ Vancouver, British Columbia, Canada}

\section{REFERENCES}

1. Zamboni P, Menegatti E, Bartolomei I, et al. Intracranial venous haemodynamics in multiple sclerosis. Curr Neurovasc Res. 2007;4(4):252-8.

2. Tallantyre EC, Brooks MJ, Dixon JE, et al. Demonstrating the perivascular distribution of MS lesions in vivo with 7-Tesla MRI. Neurology. 2008;70(22):2076-8.

3. Talbert DG. Raised venous pressure as a factor in multiple sclerosis. Med Hypotheses. 2008;70(6):1112-17.

4. Weir B. Multiple sclerosis- a vascular etiology? Can J Neurol Sci. 2010;37(6):745-57.

5. The Society of Neurological Surgeons [cited 2010 July 25]. Available from: <http:/www.societyns.org/society/bio.aspx? MemberID $=3722>$

6. CTV News [cited 2009 Dec 15]. Available from: <http://watch. ctv.ca/news/clip247004\#clip246910>http://watch.ctv.ca/news/cl ip247004\#clip246910.

7. The Globe and Mail [cited 2009 Nov 25]. Available from: http://www.theglobeandmail.com/news/national/researcherslabour-of-love-leads-to-ms-breakthrough/article1372414.

8. Panaceia or Hygeia. Available from: http://medicalmyths. wordpress.com/2009/11/24/the-zamboni-myth-ccsvi-surreal/.

9. Doepp F, Friedemann P, Valdueza JM, Schmierer K, Schreiber SJ. No cerebro-cervical venous congestion in patients with multiple sclerosis. Ann Neurol. Epub 2010.

10. Krogias C, Schroder A, Wiendl H, Hohlfeld R, Gold R. Chronic cerebrospinal venous insufficiency" and multiple sclerosis: Critical analysis and first observation in an unselected cohort of MS patients. Nervenarzt. 2010 Jun;81(6):740-6. (German) 